\title{
Research on the Configuration of the Medical Facilities for Elderly of Rural Community
}

\author{
Wang Ping, Zhu Min, Wang Wen \\ School of Management, Xi'an University of Science and Technology, Xi'an, China \\ Email address: \\ 420199253@qq.com (Wang Ping),1192420001@qq.com (Zhu Min),790269508@qq.com (Wang Wen)
}

To cite this article:

Wang Ping, Zhu Min, Wang Wen. Research on the Configuration of the Medical Facilities for Elderly of Rural Community. Humanities and Social Sciences. Vol. 5, No. 6, 2017, pp. 210-214. doi: 10.11648/j.hss.20170506.13

Received: September 25, 2017; Accepted: October 8, 2017; Published: November 30, 2017

\begin{abstract}
The extreme shortage of old-age service facilities in rural areas in China is in sharp contrast with the growing elderly population, which leads to the increasingly conspicuous rural pension problems. To do well the configuration of medical facilities is very important to the improvement of the old-age facilities system. This paper takes the community as the research area of the town of the pavilion in Shaanxi Province, takes the optimal location of the medical facilities space in the rural community as the research object, and uses the GIS method to optimize the location of the medical facilities space layout. The results show that the existing medical facilities in the store community are too concentrated in the central administrative Region, the overall distribution of medical facilities is not balanced, and the resources of medical facilities in the surrounding elderly population are scarce. The results obtained by optimizing site selection can provide scientific reference for the layout of medical facilities in future research area.
\end{abstract}

Keywords: Rural Communities, Community Medicine, Elderly Medical, Spatial Analysis

\section{Introduction}

As a large agricultural country, the number of rural population, according to the sixth national Census data shows: rural population accounted for $50.32 \%$ of the total population, of which the rural 60-year-old proportion of the elderly population is more than 60 of the total number of old people in the country $57.13 \%$. By comparative analysis, the rural population of our country is higher than that of the population in the age of aging and the base of the aging population. With the deepening of China's reform and opening up and the progress of urbanization, farmers are no longer confined to the land they have been plowing for generations, and a large number of affluent laborers in the countryside are pouring into the cities [1]. At the same time, the rural family structure has been shrinking, function has been weakening and differentiation, rural areas began to appear miniaturization characteristics. Therefore, compared with the urban endowment problem, the endowment of the rural area of our country faces the bigger challenge [2].

The highest frequency of use of older persons at all levels of service facilities is at the nearest community-level facility, because of the short radius and comprehensive coverage of community-level service facilities, it can meet the daily needs of the elderly, so as to make the family's old-age pension a success, and truly achieve the "home-aged as the main body, the community support" [3]. However, according to the research conducted by existing scholars on community elders, the satisfaction degree of the elderly to the community service facilities is not high, and the relative contents, scale and layout of the old people still have a great improvement space. And when the body function of the elderly falls, the ability to withstand disease declines, the demand for and reliance on medical facilities is greater, and the elderly are more dependent on neighboring medical facilities because of mobility problems. As a result, there is a higher demand for medical facilities in areas with an aging population, and the distribution and allocation of medical facilities should also take due account of the needs of the elderly population. 2016 State Council promulgated "on the overall liberalization of the old-age service market to improve the quality of old-age services" [4] Proposed, "Rely on the rural community comprehensive service facilities, expand the function of old-age service." This shows that the Government is very 
determined to speed up the construction of old-age service facilities in rural communities to assist the elderly in the home. In addition, the aging trend has seriously affected China's overall development, elderly groups of old age, medical security and other aspects of the demand for pressure gradually increased. According to statistics, the elderly have $60 \%$ of emergency, $49 \%$ of hospital days, $85 \%$ of long-term care beds, and it occupies about $55 \%$ of the medical expenses, do a good job of medical facilities, to the improvement of the old-age facilities system is very important [5].

In foreign countries, scholars have been studying the medical facilities based on GIS. The American scholar compiled the Dartmouth Medical Service Atlas, that "the accessibility indicators in geography play a decisive role in the health sector," and that the total amount of medical spending depends on the location of the medical facilities. The study has been used in many studies to estimate the best location for a new clinic and hospital, taking into account existing facilities, transportation supply, hourly traffic flow and population density, and minimizing the distance between patients to new clinics and hospitals. In China, the research of GIS in medical and health is mainly focused on the rationality of the status of the medical facilities, the evaluation of the accessibility and the analysis of the location of medical facilities. Congassen, Wang and other people based on the theory of accessibility, based on GIS network and spatial analysis technology, using improved potential model and two-step mobile search method, the population and Hospital of Dalian community are superimposed and analyzed, this paper probes into the spatial distribution of the Dalian Zhongshan District, Xigang, Shahekou District population and two-level hospitals by interpolating the standardized accessibility values, and evaluates the medical accessibility of Dalian [6]. Wang Yuanfei A method of calculating the geographical accessibility based on GIS and Voronoi polygon is proposed. This paper studies the geographical accessibility of medical facilities in the area of Pudong New Area in Shanghai, and analyzes the service carrying capacity of each hospital with the attribute data such as population distribution, and this method provides an important tool for the planning and decision-making of public service facilities such as medical facilities [7].

Domestic research on the health of the elderly has started late, mainly focused on the needs of the elderly health care, utilization and health care policies, although the number of research results in recent years has increased, however, the research angle is relatively single, in this context, this paper chooses the Changwu County Ting Kou Town Run store community in Shaanxi Province as the research object, and carries on the thorough research to the medical facilities disposition and the spatial layout suitable aging service status in the administrative area. The configuration of the existing medical facilities in the research subjects was studied from the perspective of spatial layout to see if the existing medical facilities were reaching the maximum efficiency in serving the elderly. [8]

\section{Current Situation in the Field of Research}

The selected sample area of the institute is the township of the town under the jurisdiction of the store community, the area in 2011, the town of the township into the pavilion. The area is located in the southeast of Changwu County, Shaanxi Province, is located in the northern part of the eastern Plateau with the transition zone, Changwu County in the southeast, from the Changwu County 12.5 kilometers, National Highway 312 line through the border. East by Bin County, North neighbour Town, west, south and Zhen border, elevation in 847-1274 meters, the total area of 32 square kilometers, the total population of 10,300 people (six data). Community jurisdiction of the second factory village, Baogai Village, Cui Jia men Village, Xie Jia he village, Hill Village, Ma Wu Village, Li Village, ran Dian Village, Xia Meng Village, Shang He, Shan Zhuang, Er'chang, Shang Meng, a total of 11 villages. [9]

According to the Ministry of Civil Affairs published in 2016, "2015 Social Services Development Statistics Bulletin" shows that by the end of 2015, our country 60 years old and above 222 million people, accounting for the total population of $16.1 \%$. And Ran Dian community 11 villages in a total of 6 administrative villages in more than $16.1 \%$, of which the ceremony village elderly population ratio reached $18.7 \%$, that the region has fully entered the "Elder" society. From the analysis of the distribution of the elderly population, Li Village, Shang Meng, Xia Meng, Cui Jia men, Ran Dian village's old population density is higher than the whole population of the village, this also reflects the demographic structure of these areas have a significant aging trend, Ran Dian community population aging problem has been very prominent, and a large number of elderly population distribution, will increase the demand for medical facilities in the region. [10]

By the following table 1, the elderly population ratio is the highest in the village, but the number of medical facilities and medical staff is not the highest in all the villages in the Ran Dian community, while the medical facilities in the second factory village as the central village are the best in the whole community, but the total number of elderly people and the percentage of the population are not From the analysis data, it can be found that the distribution of medical facilities in the Ran Dian community does not match the proportion of elderly population, from the layout of the elderly medical facilities, the concentration in the second factory village, Xia Meng, the 2 of the medical facilities in the total number of villages in the whole Ran Dian community 36.84\%. But for the elderly population distribution more concentrated Ma Wu, Ran Dian, the distribution of facilities is very few. This shows that for these elderly population concentration, but also the lack of elderly medical facilities allocation of the village should be the focus on the Institute's attention. 
Table 1. List of elderly people and medical care in Ran Dian.

\begin{tabular}{llllll}
\hline Village name & Elderly population & population & Old age population ratio & Number of medical facilities & Number of medical personnel \\
\hline Xia Meng & 82 & 476 & $17.2 \%$ & 1 & 3 \\
Shang Meng & 195 & 1108 & $17.6 \%$ & 1 & 3 \\
Cui Jia men & 120 & 715 & $16.8 \%$ & 1 & 2 \\
Li & 223 & 1194 & $18.7 \%$ & 1 & 1 \\
Ma Wu & 207 & 1290 & $16 \%$ & 2 & 2 \\
Xie Jiahe & 124 & 700 & $17.7 \%$ & 4 & 7 \\
Er'chang & 111 & 752 & $14.8 \%$ & 2 & 2 \\
Ran Dian & 206 & 1130 & $18.2 \%$ & 1 & 1 \\
Bao Gai & 141 & 951 & $14.8 \%$ & 1 & 2 \\
Shang He & 85 & 549 & $15.5 \%$ & 2 & 2 \\
Shan Zhuang & 87 & 615 & $14.1 \%$ & & 2 \\
\hline
\end{tabular}

Data source: According to the 2015 store community land right data statistics.

\section{Spatial GIS Evaluation of Medical Facilities}

\subsection{Status Quo of Medical Facilities in Research Area and Age - Appropriate Analysis of Spatial Density of Facilities}

The shortest average distance between village streets and administrative village clinics is about $400 \mathrm{~m}$. For the convenience of calculation, the effective service area of medical facilities at health service stations and village clinics is set to be $1000 \mathrm{~m}-2000 \mathrm{~m}$ and $500 \mathrm{~m}-1000 \mathrm{~m}$, respectively. Since the study area is mountainous rural and the road network is greatly and sparsely affected by the topographic changes, the service area in ArcGIS's network analysis is used for analysis. Through the traffic network data sets, paths leaving all directions of the facilities are generated, each The end of the path is connected to form the largest service area for the medical facility. Ran Dian community to provide medical services for the elderly 1 Class A health station and 18 health services, with a radius of 500 meters service coverage can be a wide range of coverage to the administrative area of the elderly population of the residential area ( However, some settlements are still not covered by the supply points of facilities and the southeastern and western parts of the study area are sparsely covered. If the service radius is 1000 meters, the service coverage area can cover a large area of residents' needs, but it is inconvenient for the elderly who have mobility problems to travel a long distance.

The population density of the elderly in the study area varied from 6.1 to 169.8 in different regions and the population of the elderly population was unevenly distributed. The distribution of medical facilities in "Er'chang - Cui Jiamen - Xie Jiahe" and "Ma Wu - Xia Meng" corresponded to the elderly population. However, the facilities in the southern, eastern and western parts of Ran Dian Community were not commensurate with the distribution of the elderly population. The number of facilities put into operation in such villages as Ran Dian Village, Xie Jiahe Village, Bao Gai Village and Ma $\mathrm{Wu}$ Village located in these locations is increased. According to the administrative village can reach the optimal medical coverage of the elderly, the need to cover four administrative villages.

\subsection{Analysis of the Adaptability of Facilities Service}

The Voronoi graph method can be used to divide the service range of medical facilities, and use the Voronoi polygon analysis tool to generate the analysis diagram of medical facilities. The graph of 19 medical facilities in the Ran Dian community was analyzed by the Voronoi graph method, which was cut by the local area mask. Then the service range of the facility point (Voronoi polygon area representation) is divided into four grades according to the area of each polygon, and then rendered into different areas, the service range of each facility point is graded. There is a facility point in each Voronoi polygon which is the service area or scope of the facility point.

The Voronoi polygon shows that the scope of the medical facilities is not very large, because the number of facilities in the area is very high and it is convenient for the villagers to find facilities in the area. On the other hand, the Voronoi polygon area is larger, indicating that the facilities of the area is less, and the service range of each point is relatively large, the old people can not easily access the health service at close range. Polygon area in the middle is smaller than that of the periphery, and the polygon area in the south is larger. The medical facilities in the store community are mainly concentrated in the central area, the distribution of medical facilities in the South is obviously inadequate, because it is related to the local terrain, most of the southern part of the mountainous terrain, and sparsely populated, and central village-the second factory village, 312 National Road, and as a central village, a variety of facilities resources are complete. Therefore, in view of the principle of equalization of public service facilities, some medical facilities should be planned in these areas to facilitate the elderly in the various villages.

The classification of the number of digits is very useful for linearly distributed data. The bitwise method ensures that each class contains an equal number of factors. The number of decimal places is assigned a quantity of equal data values for each class, there are no empty classes, and there are no classes with too many or too few values. The service area is divided into three classes by $0 \mathrm{~km}^{2}, 0.8 \mathrm{~km}^{2}$ and $1.9 \mathrm{~km}^{2}$ four-bit values. Tyson's polygon area is less than $0.47 \mathrm{~km}^{2}$ indicated that most of the old population distribution points within the service area of the facility point were within 680 metres from the 
facility point, taking into account the impact of the road network, it was easy to find the elderly medical facilities at a distance of about 700 metres on foot. These facilities are mainly concentrated in the second factory village, Li village, Xia Meng and Cui Jiamen village and the local area of Bao Gai Village. Tyson's polygon area is between $0 . \mathrm{km}^{2}$ and 0.8 $\mathrm{km}^{2}$, indicating that, within the service area of the medical facility, the elderly are required to reach the nearest facility at a distance of about 700 m-900 metres; Tyson's polygon area is larger than $1.9 \mathrm{~km}^{2}$ This kind of, reflects the old people to find medical facilities near the distance of more than 2000 meters walk, generally speaking, for residents, especially the elderly group, the nearest trip to the doctor will feel very inconvenience.

Statistics show that the service range of the community medical facilities in the store is $1.3 \mathrm{~km}^{2}$, the average value is $1.9 \mathrm{~km}^{2}$, the standard deviation is $1.5 \mathrm{~km}^{2}$, indicating that the level of medical facilities in the store community is generally moderate, but the service range of the facilities is quite different. Ran Dian community's medical facilities point most concentrated, the most convenient service area is generally central and northern distribution, the overall distribution in the central village-second factory village; the relatively sparse areas of the southern and western regions, such as Xie Jiahe, Bao Gai, Ma Wu and other areas of medical facilities, make the area of medical facilities in these areas a larger area, where older persons find it less convenient to locate nearby medical places and therefore need to be put in place in these areas. According to each Tyson Polygon, which contains only a medical facility points, each area of the medical facility's point of coverage is divided into the Tyson area, which represents any area where the distance to its associated point is closer to any other pension facility point. Calculate the aging population in each polygon, and if the number of older people exceeds 100 , a new facility candidate is needed in the polygon. Each more than 100 people need to add a new, it should be in ran shop village, Baogai, $\mathrm{Ma} \mathrm{Wu}, \mathrm{Li}$ Village, respectively, the establishment of 4 new health service stations. the provision of old age facilities clearly meets the needs of the elderly in these areas for medical facilities and is more in line with the characteristics of fair and balanced public facilities.

It is noteworthy that the Voronoi polygon analysis does not take into account the traffic network factors, which will cause the discrepancy with the actual reality. In reality, a settlement located within the confines of the medical facilities service may require a long way to reach the facility point. For example, Bao Gai village, Xie Jiahe village, the southern area of the mountain terrain, originally on the map looks very close to the medical facilities, but because of terrain, road impassability, can not enjoy the resources of this facility, only to have access to the other nearby medical facilities access point. However, In generally, this error has little effect on the analysis of Facility point space on a smaller scale map, so the reliability of the results is within acceptable range.

\subsection{Analysis of the Adaptability of Facility Space}

In Arc GIS, based on the existing road network of the store community, a recent facility point analysis model using Network analyst was established to analyze the distance from the elderly population distribution point to the nearest medical facility, first of all, we need to build the network analysis data set based on the road network in the store community, then create a new facility point analysis model, and finally solve the distance analysis from the old population distribution point to the nearest medical facility.

Table 2. Statistics on the distance from the elderly population to the nearest medical facility.

\begin{tabular}{lllll}
\hline \multirow{2}{*}{ Administrative village name } & $<\mathbf{5 0 0 m}$ & & $>\mathbf{5 0 0} \mathbf{m}$ \\
\cline { 2 - 5 } & Number of Older Persons & proportion & Number of Older Persons & proportion \\
\hline Xia Meng & 58 & $70.7 \%$ & 24 & $29.3 \%$ \\
Shang Meng & 180 & $92.3 \%$ & 15 & $7.7 \%$ \\
Cui Jia men & 78 & $65.0 \%$ & 42 & $35.0 \%$ \\
Li & 115 & $51.6 \%$ & 108 & $48.4 \%$ \\
Ma Wu & 170 & $82.1 \%$ & 37 & $17.9 \%$ \\
Xie Jiahe & 78 & $62.9 \%$ & 46 & $37.1 \%$ \\
Er'chang & 88 & $79.3 \%$ & 23 & $20.7 \%$ \\
Ran Dian & 76 & $36.9 \%$ & 130 & $63.1 \%$ \\
Bao Gai & 85 & $60.3 \%$ & 56 & $39.7 \%$ \\
Shang He & 33 & $38.8 \%$ & 52 & $61.2 \%$ \\
Shan Zhuang & 52 & $59.8 \%$ & 35 & $40.2 \%$ \\
total & 1013 & $64.1 \%$ & 368 \\
\hline
\end{tabular}

According to the statistics of the above analysis results, the distribution of the elderly population to the nearest medical facilities is less than 24 of the settlements, accounting for $64.1 \%$ of the total accounted for half of the total supply of facilities, it can be seen that the existing medical facilities in the store community is better for the elderly, but still some of the village residents to reach the medical facilities is not very convenient, a total of 6 elderly population distribution points reached the nearest distance of medical facilities beyond $1000 \mathrm{~m}$, Some of the demand points for the more $\mathrm{Ma} \mathrm{Wu}$ village exceed $2000 \mathrm{~m}$. Through the analysis of the distance between the elderly population distribution points and the nearest medical facilities, it is indicated that the spatial distribution of medical facilities in this area still needs to be perfected and improved for the elderly population in the region. Not meeting a large part of the elderly people's 
willingness to medical facilities, to a large extent, to reduce the health care facilities in the store to the aging service level, but also to a large extent, affect the utilization of health services. Therefore, it is necessary to optimize the spatial layout of the medical facilities in the community to meet the needs of the elderly in the area and to realize the "15-minute health Service Circle" in the district.

\section{Conclusion}

This paper makes an in-depth analysis on the proposition of the space allocation optimization of the elderly medical facilities in ran store. The general characteristics of elderly population distribution and medical facilities layout in Ran Dian were summarized. Based on the comprehensive accessibility of medical facilities, the coverage of medical facilities and the spatial density of facilities, the convenience degree of the elderly is evaluated. Finally, the paper puts forward the optimization scheme of the new medical facilities space allocation, optimizes the location of the new facilities, and compares and evaluates the optimization. The main conclusions obtained include:

The spatial configuration of elderly medical facilities in Ran Dian is not matched with the distribution of old population in the area, and the spatial pattern of demand and supply is not harmonious. The problem of population aging in the community of Ran Dian has appeared in various villages, and the layout of medical facilities is still concentrated in the central village and its surroundings, the space distribution. In recent years, the medical and health undertakings in Shaanxi Province have been growing steadily, but the level of medical facilities in local areas still needs to be improved to meet the increasing demand and supply balance. The resource distribution of geriatric medical facilities in the store is uneven, and the spatial pattern is a center outward extension. From the perspective of comprehensive accessibility of medical facilities, there is a tendency of agglomeration in the central village and its vicinity. In the whole research area, the service supply of medical facilities is slightly smaller than the demand. Good medical facilities are still concentrated in the village and surrounding areas of community Centre Village, the limited access to roads, the weakening of medical facilities for more remote areas, the urgent need to plan for a village-level health facility to meet the medical needs of the local elderly population.

The research process of this paper can be applied to the new research fields such as the spatial layout of public facilities in rural areas. This article takes the Changwu County Pavilion mouth town ran shop community to do the demonstration analysis, it can be extended to similar regions, it has realistic research significance, not only provide data support and planning strategy for planning department, but also provide scientific basis and reasonable optimization plan for solving the problem of regional medical facilities layout.

\section{Acknowledgements}

Fund Project: National Social Science Funds. Dynamic Evolution of Family Structure and Intergenerational Support in Rural Elderly (17BRK020); Shaanxi Province soft science research project: social network perspective Shaanxi rural community old-age system construction research (2015KRM079); Shaanxi Provincial Department of Education key scientific research plan "labor transfer on the impact of farmers' energy consumption mechanism" (15JZ037); Shaanxi Provincial Social Science Union project "new urbanization in Shaanxi agricultural population transfer and rural energy consumption development research" (2017Z018).

\section{References}

[1] Wang Ping, Zheng Yanan, Gu Jingge. Study on the Impact of Labor Transfer on Farm Household's Coal Consumption - An Empirical Study of Shaanxi Rural [J]. Journal of Xi'an University of Science and Technology, 2016 (04): 554-559.

[2] Wang Ping, Lian Yawei, Li Shuzhuo. Effect of Living Arrangement on Cognitive Function of Rural Elderly-12-Year Follow-up Study [J]. Journal of Population, 2016, (05): 92-101.

[3] Du Xianyi. Labor outflow of rural elderly in the elderly pension and mental health research [D]. Xi'an: Xi'an University of Science and Technology, 2013.

[4] "on the full liberalization of the pension market to enhance the quality of pension services, a number of opinions" Guo Fa [2016] No. 91 [Z].

[5] Zhang Jingqiu, Liu Huan, Qi Yingqian. Beijing urban elderly living environment and life satisfaction analysis. Advances in Geography, 2015, 34 (12): 1628-1636.

[6] Fu Jiasen, Wang Li, Zhao Dongxia, Wang Lei. Study on spatial accessibility of medical facilities based on GIS-Taking Dalian city as an example [J]. Journal of Surveying and Mapping Geography, 2015, 04: 102-105.

[7] Wang Yuanfei. Application of GIS and Voronoi Polygon in Geographic Accessibility Analysis of Medical Service Facilities [J]. Surveying and Mapping Geography, 2016, 03: 77-80.

[8] Chin-Hsien Liao, Hsueh-Sheng Chang, Explore Urban Flood Vulnerability based on Spatial Pattern in Taiwan Ecological City Viewpoint [J]. Landscape and Urban Planning, 2011, 3: 306-314.

[9] Cromely E K, Shannon G W. Locating ambulatory medical care facilities for the elderly [J]. Health Services Research, 21(4): 499-514.

[10] Le Grand, J. Inequalities in Health: Some International Comparisons [J]. European Eeonomic Review, 1987, 31(1): 182-191. 